\title{
The Search for the Adaptable ICT Student
}

\author{
Glen Van Der Vyver \\ University of Southern Queensland, Toowoomba, Australia
}

vandervy@usq.edu.au

\section{Executive Summary}

The 'new' ICT professional should be an articulate problem-solver who understands business and technology, in particular how technology can solve business problems. Furthermore, the ideal ICT student should be adaptable. The adaptable student embraces change, learns quickly, understands the job market, thrives on variety, is autonomous, predicts change, and acts as a change agent in the organization.

This study examines the adaptability of a sample of second-year Australian ICT students. The evidence suggests that these students are less adaptable than might be expected of people who have chosen to study a subject characterized by change. One reason for this might be the fact that these students have limited knowledge about the realities of work in ICT beyond negative perceptions about stress and long hours. A small number of more mature students with some work experience appear to be more adaptable.

An interesting paradox emerges. Younger students in particular appear to be highly adaptable in their personal lives and seek careers that maximize personal choice. On the other hand, they still prefer a degree of stability, a relatively defined career path, job security, and a career that is relatively stable.

Keywords: ICT Career, change, adaptability, ICT profession, student

\section{Introduction}

We live in an era characterized by rapid change and a crucible of that change is the ICT industry. Most ICT professionals find themselves under constant pressure as they strive to deliver ever more complex technologies in the presence of increasingly severe constraints and a paradigm shift in the ICT profession. Although the effects of change are pervasive and few of us are immune to them, they are virtually a constant in the lives of many ICT professionals.

Not everybody is equally well equipped to deal with constant change and uncertainty. Indeed, some people find it difficult to function in highly unstable, changing environments. Although there might be some niches within the ICT industry for such people, on the whole they are likely to find the life of an ICT professional stressful and even threatening. Even professionals who do

Material published as part of this publication, either on-line or in print, is copyrighted by the Informing Science Institute. Permission to make digital or paper copy of part or all of these works for personal or classroom use is granted without fee provided that the copies are not made or distributed for profit or commercial advantage AND that copies 1) bear this notice in full and 2) give the full citation on the first page. It is permissible to abstract these works so long as credit is given. To copy in all other cases or to republish or to post on a server or to redistribute to lists requires specific permission and payment of a fee. Contact Publisher@InformingScience.org to request redistribution permission. not occupy technical roles are highly exposed to the challenges of change and are often responsible for implementing the strategic organizational change that emanates from technological innovation. Indeed, in many organizations, ICT professionals have become critical agents of change.

A wealth of research has been conducted into the key skills and the psy- 
chological, social, and attitudinal dispositions that lead to success in various career paths. A limited amount of this research has focused on ICT professionals and little on what has become a key requirement: the ability to adapt to change and uncertainty. This study focuses on the extent to which ICT students appear to be adaptable to rapid change and uncertainty. It seems reasonable to surmise that people who choose to study ICT have some idea of the rewards and challenges that await them in the world of work and of the fact that a career in ICT is best suited to those who embrace change. Further, those who are comfortable with change will be attracted to ICT and those who seek security and certainty will self-select out of ICT.

The point of departure of this study is, therefore, the hypothesis that ICT students will exhibit substantive adaptive dispositions and be open to careers that involve uncertainty and change. The study further hypothesizes that ICT students will favor flexible, decentralized, and innovative work arrangements.

\section{Predictors of ICT Career Success in a Changing Workplace}

In the business world of today, change is the constant. Survival depends upon innovation, flexibility, and an adaptive mindset (Drucker, 1985, 1988; Kanter, 1983). Information Technology is a key enabler of change and nowhere is change more pervasive than in the ICT workplace (Freeman \& Aspray, 1999; Gallivan, 2004; Straub \& Watson, 2001). Information Technology products often have much shorter life cycles and are sometimes obsolete at a stage when products in other industries remain in their infancy (Cairo, Kritis, \& Myers, 1996). Information Technology thrives on innovation and the past few decades have witnessed the innovation imperative progress inexorably upward in the scale of organization imperatives, from desirable through essential to a necessity for survival (Cairo et al., 1996; Freeman \& Aspray, 1996).

Professionals working in ICT should expect the pace of change to increase and should prepare themselves for a job market that is unpredictable (Weber, 2004). It is a well established dictum that ICT workers must continuously adapt to new technologies and approaches or face the real risk of technical obsolescence and the fact that they are unemployable in the field (Freeman \& Aspray, 1999; Sumner, Yager, \& Franke, 2005). Now, this is no longer sufficient. Structural changes at the macro-economic level have made the competition for ICT positions more severe and the ICT workplace is undergoing a paradigm shift (Weber, 2004). ICT professionals will need to do more than adapt to new technologies: in many cases, they will find that their current job category no longer exists (Weber, 2004).

Even as ICT skill sets become rapidly obsolete, they are supplanted by other skill sets that are often unpredictable. Therefore, labor shortages emerge in certain niche areas (Agarwal \& Ferratt, 1998; King, 1997) and, paradoxically, this can lead to a situation where many ICT professionals are unemployed while there are labor shortages in the industry as a whole. The emergent paradigm requires much more of ICT professionals than the constant upgrading of technical skills (Sumner et al., 2005). ICT professionals must now understand technology and develop high-level business, management, and communication skills (Potosky \& Ramakrishna, 1998). Therefore, in order to survive, ICT professionals will "need the know-how and the psychological make-up to function in a turbulent job market in which the boundaries and requirements will constantly change" (Sumner et al., 2005, p. 79).

Exposure to continuous change can seriously undermine the health and wellbeing of human beings, particularly those who are not well equipped with coping mechanisms. ICT professionals have high levels of stress and work exhaustion (job burnout) (Moore, 2000) and the issues discussed above play a role in the etiology of this problem. Work exhaustion and occupational stress have long been a key issue in the ICT workplace and it would be simplistic to claim that change 
and uncertainty alone are responsible. The antecedents of work exhaustion are many and complex and include high pressure situations where there is little support or understanding from others (Moore, 1998), the need for constant re-training and re-invention (Cairo et al., 1996; Sethi, King, \& Quick, 2004), and deadlines and user demands (Sethi et al., 2004). Career concerns directly related to technological change and ICT career paradigm shift are a major cause of work exhaustion. ICT professionals are stressed by the demands placed upon them and the hours they work and this stress is exacerbated by fears about a tight job market, lack of job security, and career development issues (Pawlowski, Kaganer, \& Cater, 2004; Sethi et al., 2004).

The ICT professional of today, therefore, requires a much wider range of skills as well as the ability to cope with the particular demands of the profession. Although the actual requirements for success in the profession vary according to the particular niche occupied by the professional, the majority of ICT professionals will require technical knowledge, business and communication skills, and personality and attitudinal attributes that facilitate the potential to cope with change and uncertainty. For many, just surviving will be highly stressful.

Relatively few studies have been conducted into the attributes that will contribute to effective job performance in the emerging ICT paradigm (Gallivan, 2004) although previous studies have examined a number of relevant attributes including problem-solving and the ability to address complex business problems (Wynekoop \& Walz, 1999), academic performance (Lee, 1986), communication and interpersonal skills (Green, 1989; Lee, 1986), gender and other biographical factors (Gallivan, 2004), and extraversion (Clark, Walz, \& Wynekoop, 2003).

A number of studies have examined the role of the personality characteristics of ICT employees and students (Rosenbloom \& Ash, 2005; Teague, 1998). These studies suggest that successful ICT professionals have distinctive personality traits and cognitive dispositions. Teague (1998) used the Myer-Briggs Indicator and matched the personality type of ICT professionals with their stated preference for work as analysts, designers, or programmers. She found significant personality differences by preferred ICT occupational type and some evidence to support the conception of the introverted, task-oriented specialist programmer as opposed to the extravert, communication-focused analyst. Cegielski and Hall (2006) argue that programmers prefer to work alone, are highly problem-focused, and seek to address issues rationally and methodically. They propose a model that predicts OO (object-oriented) programming performance. The model proposes that values, cognitive abilities, and personality predict performance. They found substantive evidence to support their theory and argue that personality is the most powerful predictor.

Peslak (2006) examined the influence of personality attributes on performance in an ICT project team. He found that project grade was predicted by extraversion, an analytical disposition, and a lifestyle that values structure and order. Several other studies support this work and suggest that there is a degree of congruence between the personalities of systems analysts (or designers) and end users (Bradley, 1997; Kaiser \& Bostrom, 1982).

Adaptability is one of the key skills required of people who wish to build a career in the ICT industry but it has not featured at all prominently in previous empirical research. Indeed, some of the attributes that are deemed important for more technical people are related to order, predictability, and structure (Skowronski, 2004; Teague, 1998; Wynekoop \& Walz, 1999). These attributes are likely to be negatively correlated with adaptability, and some scholars have recognized that organizations need to make provision to accommodate key technical staff who struggle to operate within the paradigm of constant change (Skowronski, 2004).

Some important work has been done on ambiguity and the degree to which a person is open to experience. Several studies have shown that role ambiguity is associated with negative occupational outcomes, for example, stress, high turnover, and burnout (Baroudi, 1985; Gallivan, 2004; Igbaria \& Guimaraes, 1993; Moore, 2000). Some people have a greater tolerance for ambiguity 
than others and these people are better able to cope with complex, unpredictable environments (Gallivan, 2004). In a study of ICT professionals, Gallivan (2004) postulated that those who were tolerant of ambiguity and open to change would report higher levels of job satisfaction and would receive better assessments from their managers than others. The hypotheses confirming job satisfaction were confirmed but those relating to assessment were not.

The Gallivan study was limited in scope and further work is required. The discrepancy between self-perceptions of performance (assuming this is related to job satisfaction) and managerial perceptions of performance is of particular interest. It could be that employees who reported high levels of tolerance for ambiguity and openness to change were simply attempting to repress their difficult and even unbearable work conditions. They might also have overestimated their contribution. Alternatively, it is possible that tolerance for ambiguity and openness to change might make people happier and more accepting of change but in terms of actual measurable performance they might do no better than those who appear to be less adaptable. Whatever the truth may be, the ambiguous result of the Gallivan study reinforces the need for more detailed work in the area of adaptability.

Adaptability pertains to flexibility and the presence of attributes and attitudes that facilitate constant learning, the ability to identify and respond to changes in the job market, and the ability to survive and prosper in a world that is in constant flux (Bridgstock, 2006; Mirvis \& Hall, 1996). A number of ICT scholars have identified adaptability as a core requirement for success in an ICT career (Bailey \& Stefaniak, 2000; McLean, Smits, \& Tanner, 1996; Sumner et al., 2005; Wynekoop \& Walz, 1999). In the past, the focus has fallen on the ability and willingness of ICT professionals to accept change and learn new technologies and programming languages (Bailey \& Stefaniak, 2000) but the measure of adaptability has become wider and more complex. The adaptable ICT professional:

- $\quad$ embraces change (Wynekoop \& Walz, 1999);

- learns quickly, understands the job market, thrives on variety and is autonomous (Sumner et al., 2005);

- understands how technology changes and is able to predict change and adapt to it (Agarwal \& Ferratt, 1998);

- acts as a change agent in the organization (Potosky \& Ramaksrishna, 1998).

Thus, the ICT professional has become an instrument of organizational change and a subject of personal change. The influence of the ICT professional on organization change should not be viewed as a mere conduit whereby technological change is introduced. The role of the ICT professional will increasingly transcend technology and become more strategic. If any professional in the organization must be comfortable with change, it is the ICT professional.

Mahatanankoon (2006) argues that it is particularly critical that we prepare students to face an ICT workplace that is highly dynamic and always changing. A significant number of students perceive there are many negative aspects to an ICT career including change itself, a tough and competitive job market, long hours, and very low levels of job satisfaction. Many students are demoralized and question why they should devote long hours to studying technologies that may be obsolete before they leave university (Mahatanankoon, 2006). There is also evidence to suggest that some ICT students have only a vague idea about the nature of the ICT career (Mahatanankoon, 2006) and this is of particular concern because people who are fundamentally unsuited to an ICT career may be investing a lot of time and money in obtaining a tertiary qualification that may never be useful. 


\section{Methodology}

This study seeks to examine the extent to which ICT students perceive themselves to be adaptable, tolerant of ambiguity, and open to change. It also seeks to examine the extent to which ICT students understand the extent to which employment in ICT involves exposure to ongoing change, continual learning and high levels of stress and whether ICT students have a realistic perspective of a career in ICT.

The study attempts to answer the following questions:

1. Are ICT students adaptable?

2. Do ICT students understand the nature of the ICT career?

The study was conducted during a three-year period with students enrolled in a two-semester sequence focusing on database design and development. Three cohorts of students participated in the study. As the sequence is completed the year before graduation, the instructor included a number of special presentations relating to ICT careers. This included the state of the job market, writing resumes, addressing selection criteria, and talks by people who had graduated recently. In order to make the presentations more effective and targeted, students were asked to complete several questionnaires relating to their career aspirations and knowledge of the ICT job market before any presentations related to careers had been organized. The questionnaire used in this study was included.

The fourteen questions relevant to this study were based on the theoretical formulations discussed above and were presented in the form of a Likert scale. A five-point scale was used, ranging from 1 (strongly disagree) to 5 (strongly agree). Several questions on adaptability were reversed (numbers 1,2, and 4) in order to address potential bias and the scores for these questions were appropriately converted before analysis commenced. The following questions were used, grouped by category. The first eight questions focus on adaptability, the remainder on the IT career.

1. I would prefer working for a company that will offer me a long-term career and some security.

2. It takes a long time to build the skills required to do a job properly.

3. I would enjoy working in a dynamic environment where things are always changing.

4. When I am assigned a task, I prefer being told exactly what is required.

5. I enjoy trying out new things.

6. I want a career where I am free to make my own choices - for example, working hours, working conditions and tasks.

7. I would be happy to work on projects where the goalposts keep changing.

8. I would like a career that allows me to live in many different places.

9. I am confident that I will find an IT job that suits my skills and interests.

10. IT jobs are much more difficult and stressful than most other jobs.

11. The skills I have learned at university will allow me to build a good IT career.

12. In order to establish a career in IT, strong technical skills are essential.

13. IT jobs involve long hours and generally difficult working conditions

14. Most IT graduates will become programmers but a significant proportion will end up as analysts or managers. 
Potential participants were limited to all people enrolled in the two-semester sequence described above. For reasons of accessibility and availability, a convenience sampling approach was used. All students who were present during randomly selected tutorials were asked to participate but, for the purposes of this study, students who indicated that they did not intend (or were unable) to follow an ICT career in Australia were excluded. Of the sixty-five students allocated to the selected tutorials, thirty-seven completed the questionnaire. The majority of those excluded (24) were overseas students who planned to return to their country of origin or were unable to work in Australia but four otherwise eligible students indicated that they did not plan to pursue a career in ICT. No eligible student declined to participate. The gender balance was significantly skewed towards males (twenty-eight) and most of the students (thirty-one) had not previously held a fulltime job.

There are a number of methodological issues which must be addressed. The questionnaire administered in this study was presented in the broader context of an informal career guidance project. Although the questions were derived from theoretical formulations, the instrument was not validated and may not provide an adequate measurement of adaptability. The sample was also small, not randomly selected, and comprised only ICT students who were eligible to work in Australia. Furthermore, given the context of the study, only a limited number of questions were possible and a design involving a high level of statistical sophistication was not appropriate. A formal statistical comparison between various subgroups (e.g. males / females and those with / without work experience) is also problematical because of the small numbers in some of the subgroups and the possibility that confounding variables exist. Therefore, the results of this study are descriptive in nature. That being said, the study is intended to be a point of departure for further work rather than make definitive statements. It is also possible that people participating in an exercise which was likely to be of personal benefit, as is the case here, would have been more motivated and involved. Therefore, the quality of the data may be better than it would have been if students were merely given the survey in isolation.

\section{Results}

The questions on adaptability exhibited an acceptable level of reliability (Cronbach alpha $=.741$ ). Several questions did not meet the assumptions of normality although the average adaptability distribution approximates a normal distribution. The questions relating to an ICT career were marginally superior in terms of reliability (Cronbach alpha $=.794)$.

Adaptability is rated on a scale that ranges from 1 (a tendency to non-adaptability) to 5 (a tendency to adaptability). A score of 3 is neutral. Table 1 shows details for the adaptability questions.

Table 1: Statistics for questions measuring adaptability $(N=37)$

\begin{tabular}{|l|l|l|l|l|l|l|}
\hline Question & $\begin{array}{l}\text { Overall } \\
\text { Mean }\end{array}$ & Male & Female & $\begin{array}{l}\text { No Work } \\
\text { Experience }\end{array}$ & $\begin{array}{l}\text { Work } \\
\text { Experience }\end{array}$ & $\begin{array}{l}\text { Standard } \\
\text { Deviation }\end{array}$ \\
\hline 1 & 2.65 & 2.62 & 2.75 & 2.48 & 3.50 & 1.060 \\
\hline 2 & 2.89 & 2.76 & 3.38 & 2.84 & 3.17 & .936 \\
\hline 3 & 2.16 & 2.21 & 2.00 & 2.10 & 2.50 & .764 \\
\hline 4 & 3.41 & 3.31 & 3.75 & 3.42 & 3.33 & .762 \\
\hline 5 & 3.65 & 3.72 & 3.38 & 3.68 & 3.50 & .789 \\
\hline 6 & 3.49 & 3.55 & 3.25 & 3.45 & 3.67 & .989 \\
\hline 7 & 1.70 & 1.76 & 1.50 & 1.58 & 2.33 & .740 \\
\hline 8 & 2.24 & 2.34 & 1.88 & 2.13 & 2.83 & .796 \\
\hline
\end{tabular}


The average score for adaptability across all questions was 2.77 . It is interesting to note that the respondents exhibited the lowest degree of adaptability where the questions directly addressed a work environment where change was the norm (q. 3 and q. 7). The respondents exhibited a strong aversion to working in highly fluid projects and a distinct aversion for workplaces characterized by change. They were also significantly averse to moving around frequently in order to find work (q. 8).

Respondents showed the highest degree of adaptability when personal choices were involved (q. 4, q. 5, and q.6). All of these questions relate to situations where control resides with the individual. These questions had the effect of significantly raising the average score but, should a properly expanded and validated scale be built, the survival of these questions is by no means assured. They may measure the lifestyle choices of the current generation of ICT students. When these two questions are omitted the average adaptability drops to 2.54 .

Question 5 is of particular interest as it indicates a general willingness to embrace change. It would appear that, in general, the respondents are relatively open to change. This question delivered the highest adaptability score although an even higher score might have been expected from a group of respondents dominated by people who were brought up in the Information Society. A comparison of the scores reveals a paradox. There appears to be a tendency towards lifestyle adaptability which is not matched by occupational adaptability.

There was no clear difference between males (2.78) and females (2.73) in terms of overall adaptability. Although there were noticeable differences between females and males on some of the individual questions, no discernable trend is apparent. Full-time work experience does, however, appear to have a degree of influence. Students with at least one year of full-time work experience (3.10) appear to be somewhat, but not dramatically, more adaptable than those without this experience (2.71). The impact of experience is worth further examination but the analysis must be treated with caution. These students are older than the remainder of the respondents, females are more under-represented, and there is no information available about the nature of the full-time work. It is likely that some of these people worked in occupations outside ICT previously and were looking to change careers but others may have ventured into full-time work for a short period before returning to education. Given the probable diversity of the people who had previous work experience, it is not prudent to conclude anything more than that the data supports the notion that work experience does foster adaptability, particularly as regards the inculcation of attitudes which reflect the reality of the world of work.

Details for the questions that measured perceptions about ICT careers are presented in Table 2.

Table 2: Statistics for questions measuring perceptions of ICT careers $(\mathrm{N}=37)$

\begin{tabular}{|l|l|l|l|l|l|l|}
\hline Question & $\begin{array}{l}\text { Overall } \\
\text { Mean }\end{array}$ & Male & Female & $\begin{array}{l}\text { No Work } \\
\text { Experience }\end{array}$ & $\begin{array}{l}\text { Work } \\
\text { Experience }\end{array}$ & $\begin{array}{l}\text { Standard } \\
\text { Deviation }\end{array}$ \\
\hline 9 & 3.41 & 3.55 & 2.88 & 3.42 & 3.33 & 1.117 \\
\hline 10 & 3.35 & 3.34 & 3.38 & 3.35 & 3.33 & 1.136 \\
\hline 11 & 4.08 & 4.24 & 3.50 & 3.94 & 4.83 & .894 \\
\hline 12 & 4.00 & 4.10 & 3.63 & 3.90 & 4.50 & .913 \\
\hline 13 & 4.14 & 4.07 & 4.38 & 4.16 & 4.00 & 1.058 \\
\hline 14 & 3.65 & 3.79 & 3.13 & 3.71 & 3.33 & 1.296 \\
\hline
\end{tabular}

The respondents were relatively confident that they would find an appropriate job and that the skills learned at university would translate into a sound ICT career. Given a job market that was 
significantly tighter and more competitive than it is in 2008 and the rapid obsolescence of skills, overconfidence could be at play here. It should be noted that the responses to these two questions were skewed by a small number of people who had the utmost confidence in their abilities in general and their ability to find an ICT job in particular.

Students have relatively negative perceptions of ICT work (q.10 and q. 13) and continue to believe that IT careers are dominated by technical roles and the traditional division into technical specialists and managers (or analysts). The former attitude is of concern at a time when universities seek to recruit good students into ICT programs while the latter attitude indicates that many students may not be fully in touch with the realities of the job market.

The small number of students with some job experience notwithstanding, it is worth examining the differences between them and younger students. These students had a more realistic understanding of the difficulties involved in obtaining a suitable job and a relevance of the skills they were mastering but their exceptional confidence about the potential value of the skills acquired at university is surprising. They appear to have researched ICT careers in more depth because they seemed to have a better grasp of the fact that ICT is not a purely technical occupation and that new career paths are emerging. There was little difference between these students as regards their perceptions of the stress and difficulty involved in pursuing an ICT career.

\section{Conclusions}

There is evidence to suggest that ICT students are not as highly adaptable as might be expected from people who have chosen to train for a career in an area that is characterized by rapid change and uncertainty. Indeed, it would appear that students are not fully cognizant of the extent to which they will need to constantly re-invent themselves. The constraints of this study makes any discussion of the degree of adaptability ill advised but, should it be the case that ICT courses are not attracting adaptable students, the implications for students and industry are equally serious. Industry could struggle to find the right type of graduate while students could face unhappy and stressful years attempting to adapt to a career to which they are not suited.

Younger students have great potential for adaptability but seem reluctant to 'adapt' this potential to suit the realities of the job market. They are clearly keen for new experiences but still view the ICT career in relatively traditional terms. Perhaps paradoxically, mature students also view the ICT profession this way, perhaps because they are hoping to improve their lot by studying ICT.

There is also evidence which suggests that students do not know as much about the profession for which they are training as they should. Indeed, some students seem stuck in a time warp and have only a limited understanding of the paradigm shift that is taking place. Students with some work experience do however have a better picture of what is happening with ICT careers.

Perhaps the most interesting finding in this study is that ICT students seem to be somewhat negative about careers in the profession. They expect careers dominated by long hours and stress. If they were to factor in some of the challenges that appear to be discounted at present, the ICT profession might appear even less appealing.

The nature of the ICT profession is changing and we will need to attract even better students in the future than we did in the past. We need intelligent, articulate students who need not necessarily be technological experts but must have the ability to understand how technology can solve business problems. We need students who understand the demands of the ICT profession and are excited by a career in that profession. We must educate students about the nature of the profession, its rewards and demands. For those who have the right skills and attitudes, the rewards remain greater than is the case in many other professions. 


\section{References}

Agarwal, R., \& Ferratt, T.W. (1998). Recruiting, retaining and developing IT professionals: An empirically derived taxonomy of human resource practices. Proceedings of the 1998 ACM SIGCPR Conference on Computer Personnel Research, Boston, MA, $292-302$.

Bailey, J. L., \& Stefaniak, G. (2000). Preparing the information technology workforce for the new millenium. Proceedings of the 2000 ACM SIGCPR Conference on Computer Personnel Research, Evanston, Illinois, 1-7.

Baroudi, J. J. (1985). The impact of role variables on IS personnel work attitudes and intentions. MIS Quarterly, 9(4), 341-356.

Bradley, J. (1997). The effect of personality type on team performance. The Journal of Management Development, 16(5), 337-350.

Bridgstock, R. (2006). Follow your (employable) bliss. Proceedings of the AACC06 International Careers Conference, Sydney.

Cairo, P. C., Kritis, K. J., \& Myers, R. M. (1996). Career assessment and the adult career concerns inventory. Journal of Career Assessment, 4, 189-204.

Cegielski, C., \& Hall, D. (2006). What makes a good programmer? Communications of the ACM, 29(10), 73-75.

Clark, J. G., Walz, D. B., \& Wynekoop, J. L. (2003). Identifying exceptional software developers: A comparison of students and professionals. Communications of the AIS, 11(8), 137-154.

Drucker, P. F. (1985). Innovation and entrepreneurship. New York: Harper and Row.

Drucker, P.F. (1988). The coming of the new organisation. Harvard Business Review, 66(1), 45-53.

Freeman, P., \& Aspray, W. (1999). The supply of information technology workers in the United States. Washington: Computing Research Association.

Gallivan, M. (2004). Examining IT professionals' adaptation to technological change: The influence of gender and personal attributes. The DATA BASE for Advances in Information Systems, 35(3), 28-49.

Green, G. I. (1989). Perceived importance of systems analysts' job skills, roles and non-salary incentives. MIS Quarterly, 13(2), 115-133.

Igbaria, M., \& Guimaraes, T. (1993). Antecedents and consequences of job satisfaction among information center employees. Journal of Management Information Systems, 9(4), 145-174.

Kaiser, K., \& Bostrom, R. (1982). Personality characteristics of MIS project teams: An empirical study and action-research design. MIS Quarterly, 6(4), 43-60.

Kanter, R. M. (1983). The change masters: Innovation and entrepreneurship in the American organization. New York: Simon and Schuster.

King, J. (1997, October 6). IT labor emergency promotes feds to study, fix shortage. Computerworld.

Lee, D. M. S. (1986). Academic achievement, task characteristics, and first job performance of young engineers. IEEE Transactions on Engineering Management, 33(3), 127-133.

Mahatanankoon, P. (2006). What information technology major is right for me? A preliminary finding. Proceedings of SIGMIS-CPR, April 13-15.

McLean, E. R., Smits, S. J., and Tanner, J. R. (1996). The career dynamics of information systems professionals: a longitudinal study. ACM SIGCPR Computer Personnel, 17(4), 3-26.

Mirvis, P., \& Hall, D. (1996). Psychological success and the boundaryless career. In M. B. Arthur \& D. M. Rousseau (Eds.), The boundaryless career: A new employment principle for a new organizational era (pp. 237-255). New York: Oxford University Press. 
Moore, J.E. (1998). Job attitudes and perceptions of exhausted IS/IT professionals: Are we burning out our valuable human resources. Proceedings of the 1998 ACM SIGCPR Conference on Computer Personnel Research, Boston, MA, 264-273.

Moore, J. E. (2000). One road to turnover: An examination of work exhaustion in technology professionals. MIS Quarterly, 24(1), 141-148.

Pawlowski, S. D., Kaganer, E. A., \& Cater, J. J. (2004). Mapping perceptions of burnout in the information technology profession: A study using social representations theory. Proceedings of the Twenty-Fifth International Conference on Information Systems, 901-913.

Peslak, A. (2006). The impact of personality on information technology team projects. Proceedings of the 2006 ACM SIGMIS CPR Conference on Computer Personnel Research, April 13-15, Claremont, CA, $273-279$.

Potosky, D., \& Ramakrishna, H. (1998). A conceptual framework for predicting the career success of IS professionals. Proceedings of the 1998 ACM SIGCPR Conference on Computer Personnel Research, Boston, MA, 174 - 179.

Rosenbloom, J.L. and Ash, R. (2005). Big five personality characteristics of established information technology professionals. Lawrence: University of Kansas.

Sethi, V., King, R. C., \& Quick, J. C. (2004). What causes stress in information systems professionals? Communications of the ACM, 47(3), 99-102.

Skowronski, V. (2004). Do agile methods marginalize problem solvers? Computer, 37(10), 120, 118-119.

Straub, D. W. \& Watson, R. T. (2001). Research commentary: Transformational issues in researching IS and net-enabled organizations. Information Systems Research, 12(4), 337-345.

Sumner, M., Yager, S., \& Franke, D. (2005). Career orientation and organizational commitment of IT personnel. Proceedings of the 2005 ACM SIGMIS CPR Conference on Computer Personnel Research. Atlanta, GA, 75-80

Teague, J. (1998). Personality type, career preference, and implications for computer science recruitment and teaching. Proceedings of the 3rd Australasian Conference on Computer Science Education ACSE '98, 155-164.

Weber, R. (2004). Some implications of the year-2000 Era, dot-com era and offshoring for information systems pedagogy. MIS Quarterly, 28(2), iii-xi.

Wynekoop, J. L., \& Walz, D. B. (1999). Characteristics of high performing IT personnel: A comparison of IT versus end-user perceptions. Proceedings of ACM Special Interest Group on Computer Personnel Research, New Orleans, LA, $209-218$.

\section{Biography}

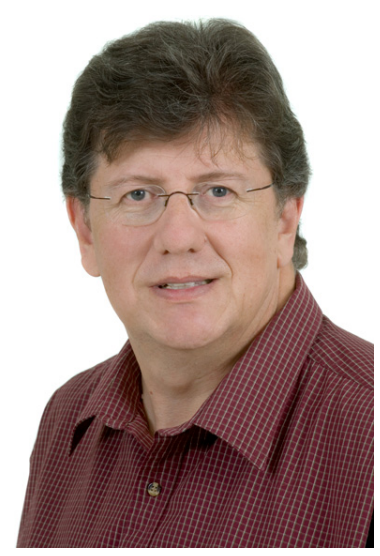

Glen Van Der Vyver is a senior lecturer in Information Systems at the University of Southern Queensland. He worked at the 'coalface'in Human Resources and IT (mostly) for around fifteen years before becoming an academic some years ago. Glen teaches primarily in the database area and is currently working on research relating to IT careers, outsourcing, off-shoring and risk perception. 